\title{
Da "Fazenda" à "Comunidade": espaços-tempos que se enraizam na região sisaleira da Bahia
}

\author{
Alessandra Alexandre Freixo
}

\begin{abstract}
resumo Neste artigo, busco compreender a pluralidade de sentidos atribuídos à comunidade na regiáo sisaleira a partir de dois pontos de partida: primeiramente, pensando a comunidade como um espaço-tempo constituído no início da década de 1970, que marca o início de um processo de mobilização social; em segundo lugar, compreendendo a comunidade como uma localidade, à medida que os processos de mobilização social ocorrem no espaço geográfico da fazenda, que passa a coincidir com a comunidade, que se torna referência não apenas do "trabalho social", mas também como um lugar. Neste sentido, podemos supor um caminho "da fazenda à comunidade", como um processo de produção de um novo espaço-tempo. Para tal análise dos sentidos de comunidade na regiáo, tomei como principal suporte as narrativas dos mais velhos moradores das localidades em estudo, bem como de lideranças comunitárias e militantes do Movimento de Evangelização Rural (MER) que atuaram na década de 1970.
\end{abstract}

palavras-chave Memória. Comunidade. Espaço-tempo. MER. Região Sisaleira.

\section{Introdução}

Essa jornada ao longo dos caminhos do sisal teve início em 2005, com minha chegada em Valente (BA) com o intuito de realizar um registro da memória das localidades rurais deste município. Ao longo deste trabalho, os mais velhos moradores dessas localidades foram eleitos como principais protagonistas na construção desse registro, à medida que estes foram considerados como legítimos "trabalhadores da memória" (Bosi, 1983) do lugar pelas pessoas que aí vivem.

Esse "lugar valente", tal como muitos do lugar denominam o município, tem seu nome vinculado a um mito de origem datado do início do século XX. Nas diversas narrativas sobre este mito, amplamente difundidas e documentadas, registra-se uma imagem de um boi "valente", que teria lutado por liberdade ou para fugir do subjugo. Esta imagem de valentia levou a uma mudança do nome da fazenda em que esse evento teria acontecido para "Fazenda Boi Valente", que deu origem ao povoado de Boi Valente (1941) e, mais tarde, ao município de Valente.

A fazenda constituiu-se, deste modo, num elemento primordial no imaginário não apenas no município de Valente, contribuindo sobremaneira para a construção de um imaginário e uma ruralidade estreitamente relacionada à criação de gado em toda a atual região sisaleira. Por outro lado, é fundamental notar o papel que a cultura do sisal adquiriu progressivamente sobre o imaginário social no lugar, tornando-se, ao lado do "boi valente", um importante símbolo, ultrapassando os limites tidos como urbanos - a sede do município. Na cidade é comum a presença de ícones como figuras da planta desenhadas em pedra-sabão nas praças, mas também presentes nos muros de prédios públicos. Tais ícones chegam a ser muito mais frequentes do que a imagem do boi valente, que está presente em uma única praça no centro comercial da cidade.

Nas diversas narrativas elaboradas pelos mais velhos moradores do lugar, a fazenda 
insinua-se como um espaço-tempo no qual estas pessoas constituíram cotidianamente suas identidades, tomando como principal elo ao lugar suas redes de sociabilidade familiar, sejam estas consanguíneas ou mesmo aquelas forjadas pelo compadrio que, em última instância, são reconhecidas como ampliaçóes de suas redes familiares originais.

Entretanto, destaca-se ainda nas narrativas desses antigos moradores um processo reconhecido como a "criação da comunidade", fenômeno que estes atribuem em grande medida às novas geraçôes e que, a depender das localidades em que se inserem estas pessoas, teria iniciado a partir da década de 1970, estendendo-se até a década de 1990. Neste processo, a igreja católica situa-se como importante protagonista, à medida que são os religiosos católicos aqueles legitimados nas narrativas como "aqueles que trouxeram a comunidade pra Valente", expressão correntemente presente no lugar.

Neste artigo, buscarei traçar algumas consideraçôes sobre este processo reconhecido como a "passagem da fazenda à comunidade", tomando como ponto de partida as narrativas elaboradas por moradores mais velhos do lugar, legítimos representantes do chamado "tempo da fazenda", bem como aquelas produzidas por algumas lideranças comunitárias, assim designadas por terem participado ou participarem ainda hoje desse processo de "criação da comunidade".

Esta pesquisa foi desenvolvida a partir de um viés essencialmente qualitativo, no qual fiz uso, principalmente, dos fundamentos téoricometodológicos da pesquisa em memória social, de acordo com o proposto por Bosi (2003). Nesse sentido, a pesquisa aqui apresentada inspira-se na metodologia da história oral, na qual a experiência de vida narrada, em diálogo com diversas fontes de coleta de dados historiográficos, passa a ser mais um instrumento de problematização e construção da história (Levi, 1996). Os recursos metodológicos uti- lizados nesta pesquisa foram a observação e o registro de dados em caderno de campo, bem como entrevistas aprofundadas, além de análise documental.

Os sujeitos desta pesquisa são, principalmente, agricultores, homens e mulheres, que vivem em diferentes localidades rurais do município de Valente (BA). Participaram da pesquisa um total de 30 agricultores, dentre eles 26 antigos moradores, com idades variando entre 65 e 92 anos, além de 4 agricultores, com idade entre 35 a 60 anos, que teriam participado, como lideranças comunitárias, desse processo de "criação das comunidades". Além dos agricultores entrevistados, foi realizada uma entrevista com um militante religioso, considerado no lugar como um dos mentores intelectuais desse movimento de criação de comunidades.

Desse modo, proponho aqui resgatar a pluralidade de sentidos atribuídos às comunidades em Valente a partir de dois pontos de partida: primeiramente, pensando a comunidade como um espaço-tempo constituído a partir do início da década de 1970, que marca o começo de um novo processo de mobilização social; segundo, compreendendo a comunidade como uma escala de lugar, à medida que, em determinado momento histórico, os processos de mobilização social sedimentam-se num determinado lugar, o que vale dizer, no caso de Valente, que o espaço geográfico da fazenda passa a coincidir com a comunidade, que se torna referência não apenas do "trabalho social", mas também como uma localidade. É neste sentido que podemos supor um caminho "da fazenda à comunidade", como um processo de produçáo de um novo espaço-tempo na região.

Ao longo do texto, trago a noção de espaçotempo, inspirada principalmente em Lefebvre (1991), que defende a indissociabilidade do espaço e do tempo, de tal modo que ultrapassam a noção tridimensional do espaco, inserindo neste mais duas dimensões: o tempo e o coti- 
diano vivido. Por outro lado, oriento-me também pela contribuição de Elias (1998), para quem espaço e tempo são dimensões indissociáveis da realidade vivida.

É sob esse viés que tomo aqui o espaço-tempo dos agricultores de Valente: espaço e tempo, dimensóes indissociáveis da realidade vivida (Elias, 1998; Lefebvre, 2005), que se constroem como significações imaginárias (Castoriadis, 1982) e se conformam na construção de um passado, que só adquire sentido por um processo de seleção da memória, à luz das experiências e vivências cotidianas (Pollak, 1989).

Diante do exposto, mais do que fazer um estudo minucioso dos processos sócio-históricos de constituiçãa das comunidades na região, principalmente a partir dos trabalhos desenvolvidos no seio da igreja católica na década de 1970 , o que se pretende aqui é partir de uma categoria nativa - a comunidade - para compreender seus sentidos no lugar e suas articulaçôes com os trabalhos desenvolvidos pela igreja, correntemente considerados como ponto de partida para a mobilização social no município, ou mesmo uma alavanca ou embrião ao desenvolvimento do lugar.

Desse modo, boa parte dos moradores mais antigos do lugar claramente delimita um espaço-tempo presente - "o tempo da comunidade", em contraposição ao "tempo da fazenda” - ao qual acreditam "não pertencer" e não "saber", por não participarem dele. Assim, em meus primeiros contatos com estes sujeitos, eu frequentemente solicitava que me contassem sobre a "história da comunidade", e era comum ouvir deles a expressão "disso eu não sei, pergunte aos mais novos". Logo, percebi a necessidade de problematizar a categoria comunidade, buscando localizá-la no espaço e no tempo, como uma construção relativamente recente e, principalmente, um processo do qual poucos dos velhos entrevistados tinham participado e, por isso, não se sentiam legitimados a narrar.
Desse modo, percebe-se aí um sentido e um recorte geracional claro: a comunidade é, em geral, o "tempo do novo", enquanto a fazenda é o espaço-tempo do velho, que até hoje permanece vivo na memória (individual e coletiva) dos velhos. É tomando esta noção espaço-temporal da comunidade que empenharei uma análise de seus sentidos. Além disso, a comunidade assume atualmente um caráter de localidade, referência não só para os jovens, mas também para os velhos, já que, como já foi sinalizado anteriormente, essas localidades, em geral, correspondem, geograficamente, à área de antigas fazendas que, de um modo geral, reproduzem antigas relaçóes de reciprocidade - principalmente o elo familiar.

De modo a explorar a diversidade de sentidos atrelados à fazenda e à comunidade no lugar, tais como estas se expressam nas narrativas dos sujeitos entrevistados, faz-se necessária uma primeira aproximação ao contexto no qual estão inseridos tais sujeitos. Assim, buscarei inicialmente uma delimitação do que historicamente se constituiu como o espaço-tempo da fazenda, a partir do qual se desenvolve a "regiẫo sisaleira" e o "lugar valente", embasandome tanto nas narrativas dos velhos moradores sobre seu passado, como em escritos produzidos sobre o lugar. A opção por esse breve registro sobre a constituição do lugar parece-me essencial para uma compreensão dos sentidos atribuidos à fazenda, um espaço-tempo anterior que fornece as bases para a constituição do "tempo da comunidade", fortemente presente nas narrativas elaboradas sobre o lugar.

Nesta breve dicussão em torno da constituição do espaço-tempo da fazenda, procedo a uma descrição das relaçóes e das redes de sociabilidade características da fazenda, que fazem com que os mais velhos a reconheçam como "seu tempo", em contraposição ao "tempo da comunidade", um tempo das geraçôes mais novas, no qual se instauram novas sociabilidades. 
A partir dessa descrição dos sentidos atribuidos à fazenda pelos mais velhos, desenvolvo uma análise dos sentidos atribuídos à comunidade, como um espaço-tempo sobreposto àquele da fazenda, a partir de distintas narrativas sobre os processos de constituição de comunidades em Valente. Inicialmente, recorro à narrativa de um militante do Movimento de Evangelização Rural (MER), movimento social reconhecido no lugar como o mobilizador da ação comunitária na região. Em seguida, tomo como base os depoimentos de moradores de três distintas comunidades, formadas em momentos históricos distintos, de modo a me aproximar desta pluralidade de significados que formam a noção de comunidade em Valente.

\section{A constituiçáo de um "lugar valente" e uma "regiáo sisaleira": demarcando o espaço-tempo da fazenda nas narrativas de velhos agricultores de Valente}

Tomando como ponto de partida a tessitura de espaços-tempos expressos nos diferentes relatos de velhos agricultores de Valente, foi possível distinguir ao menos quatro marcadores do tempo fortemente presentes, importantes auxiliares na construção de biografias e na delimitação do que estes sujeitos denominam "o tempo dos antigos", ou ainda "o tempo da fazenda". Seriam eles: o trabalho na roça, talvez o elemento estruturante mais fortemente presente em todos os relatos, que marca o "tempo da vida", em contraposição à morte; a comunidade, que delimita um espaço-tempo anterior (o "tempo dos antigos", da fazenda e da sociabilidade da infância e maturidade na família e no trabalho) e um espaço-tempo atual (ou o "tempo de hoje", tempo do qual os velhos, em sua maioria, não reconhecem participar); o sisal, que demarca o espaço-tempo da regiáo sisaleira, imagina- riamente construída no seio das fazendas, que transforma significativamente as relaçôes sociais no lugar, influenciando sobremaneira suas vivências e representaçóes; a seca, um marcador fortemente presente no imaginário do lugar, que parcela o espaço-tempo vivido em "tempos bons" e tempos ruins" e marca fortemente as relações dos velhos em seu lugar. É a partir destes marcadores espaço-temporais que não só os mais velhos, mas boa parte das pessoas do lugar, constituem suas identidades, marcadamente influenciadas pela inserção da cultura do sisal na região, a ponto de ser possível sugerir o que denomino uma "ruralidade sisaleira".

Desse conjunto de marcadores espaço-temporais, destaco aqui o sisal, que se insere no lugar já no início do século XX e aos poucos vai conformando o que hoje reconhecemos como a "região sisaleira", deixando para trás um outro espaço-tempo, o "sertão dos tocós", reconhecido como o lugar do índio, do vaqueiro e do fazendeiro, espaço este ainda fortemente presente no imaginário da regiấo e vivo na memória dos mais velhos. É a partir da cultura do sisal que começam a se desenvolver na região os agrupamentos humanos estabelecidos de longa data, originando em meados do século novos municípios na região, como o caso de Valente.

A região que hoje se delimita como "região sisaleira”, em sua quase totalidade, por muito tempo (provavelmente desde princípios do século XVII) foi constituída como o "sertão de tocós", nome atribuído ao lugar onde viviam "índios ferozes", nomeados por bandeirantes como "tocós", como relatam escritores do lugar, como Vanilson Oliveira (2002) e Orlando Barreto (2007). Dada a relevância destas terras para o escoamento da produção e a dificuldade de acesso a água, seu povoamento se deu prioritariamente ao longo dos cursos de seus principais rios, bem como nas proximidades de outros corpos de água, como olhos d'água e lagoas, que serviam como locais de repouso para 
as tropas de gado (Bahia, 1974; Oliveira, 2002; Barreto, 2007).

Grande parte das fazendas que se formaram nesta época permanecem como referência ainda hoje e compóem boa parte das narrativas sobre o passado dos mais velhos, tendo sido transformadas em povoados, ou mesmo sendo tomadas como marco de origem de novos municípios, como o caso da Fazenda Valente - que corresponderia à atual sede do município de Valente. Estas fazendas se caracterizavam principalmente por sua rusticidade, na qual havia, em geral, apenas a casa do fazendeiro (a "sede" da fazenda, como é reconhecida pelos mais velhos do lugar) e, em suas proximidades, estábulos, cercados e cabanas para agregados e vaqueiros (Pinto, 1969).

Neste cenário, onde floresciam as grandes fazendas de gado que, em sua maioria, pertenciam a um número muito reduzido de famílias, figuravam atores sociais que ainda hoje constituem importantes referências culturais do lugar, como representantes do "tempo dos antigos", ao qual se referem os mais velhos do lugar. É comum em suas narrativas os mais velhos mencionarem figuras como o "gentio", o "vaqueiro", o "cativo" e o "fazendeiro", como caricaturas do "tempo da fazenda", como heranças de um tempo no qual reconhecem terem dominado relaçóes sociais muito distintas das que hoje se reproduzem em seu lugar.

Assim, florescem entre os mais velhos os "causos" dos gentios, nos quais se faz referência ao índio como um "selvagem" e "guerreiro", que resiste no imaginário do lugar desde os tempos remotos do "Sertão dos Tocós". Também o vaqueiro, amplamente difundido como uma espécie de "representante fiel" da "cultura sertaneja”, que tem sua identidade continuamente forjada de modo a reproduzir sua imagem de "homem livre" e, sobretudo, "homem forte", está fortemente presente nas narrativas dos mais velhos. Desse modo, no espaço-tempo da fazenda, o vaqueiro figura como trabalhador livre, responsável não apenas pelo trato do rebanho, mas também de toda a fazenda, atuando geralmente como um "administrador" da propriedade. Muitas vezes, esta figura confunde-se nas narrativas com o tropeiro, já que também guiava as tropas pelos caminhos de gado.

Ao lado do vaqueiro, também participa da memória do lugar e, principalmente, das lembranças dos mais velhos, a figura do negro "cativo", importante mão-de-obra na fazenda, seja nas tarefas domésticas ou na construção de taques e aguadas para provimento de água nos períodos secos. É interessante destacar que os mais velhos, apesar de não terem vivenciado estas relaçóes de escravidão, narram com muita propriedade acontecimentos, presentificando-os como referência dos "tempos dos antigos”, no qual predominavam estas relaçōes nas fazendas, num possível trabalho de enquadramento da memória (Pollak, 1989), que os possibilita legitimar-se como herdeiros de um espaço-tempo, o "tempo da fazenda", que reconhecem como passado, mas que ao mesmo tempo se atualiza como forte elemento do seu enraizamento ao lugar.

Nestes "tempos de cativeiro", como denominam os velhos, o fazendeiro, geralmente ausente em suas terras, fixava residência em povoados próximos ou ainda em Salvador, confiando as terras a um vaqueiro, que se responsabilizava pelo trato de seu gado e seus escravos. Narram os mais velhos que grandes extensóes de terra separavam as fazendas que, em geral, pertenciam a uma mesma família, em decorrência da distribuição das terras aos herdeiros dos grandes fazendeiros da região. Esta referência familiar foi tão intensa, que mesmo atualmente é frequente vincularem-se as propriedades ou as antigas fazendas aos nomes de famílias às quais pertenceram.

É neste espaço-tempo da fazenda que se insere a cultura do sisal, planta originária do México, sendo introduzida na Bahia no início 
do século XX e florescendo como atividade econômica a partir de 1940 (Silva et al., 1999). E é também neste momento que floresce o município de Valente, que passa a ser reconhecido como a "Capital do Sisal" a partir de 1950, na região que então se constitui como "sisaleira", quando a planta começa a ser designada como o "ouro verde", tempo ao qual se remetem os mais velhos, nas suas memórias do tempo em que "sisal valia ouro".

Dentre os municípios pertencentes à região sisaleira da Bahia, Valente apresenta-se com destaque por uma importante participaçáo na produção do agave, localizando-se a nordeste do estado, a cerca de $250 \mathrm{~km}$ de Salvador. Dos 19.129 habitantes deste município, cerca de 50\% moram no campo (IBGE, 2005). Valente é por muitos considerado o "símbolo do desenvolvimento sisaleiro", ou ainda a "Capital do Sisal” (Pinto, 1969), disputando este título com o município de Conceição do Coité, do qual se emancipou em 1958 (IBGE, 2008).

No contexto de crise da lavoura sisaleira, que se estende do fim da década de 1960 à década de 1980, inicia-se, não apenas no município de Valente, mas em municípios próximos da região, um importante processo de mobilização social, encabeçado principalmente pela igreja católica, que desencadearia um processo de ressignificação do papel dos sindicatos de trabalhadores rurais e serviria ainda de berço para as principais organizaçóes não governamentais da região.

E este "lugar valente" tornou-se cenário de importantes mudanças sociais, que deram maior visibilidade ao município frente aos demais da região sisaleira, pela incorporação de novas significaçóes ao magma que constitui o lugar, principalmente no que tange à noção de comunidade que aí floresce, ora em continuidade, ora em contraposição às representações em torno da fazenda.

\section{A sociabilidade da fazenda na ótica dos velhos agricultores do sisal}

Tomando como subsídio as narrativas dos mais velhos moradores de algumas localidades rurais em Valente, proponho aqui traçar alguns elementos que caracterizam a sociabilidade da fazenda, no intuito de compreender a passagem do espaço-tempo da fazenda para aquele da comunidade, no que diz respeito tanto a rupturas e, principalmente, à continuidades nas relaçóes, continuidades estas que permitiram a instituição de um novo espaço-tempo, enfim, a constituiçáo de comunidades no seio de antigas fazendas, tal como foram reconhecidas pelos mais velhos do lugar.

Desse modo, nas narrativas desses sujeitos mais velhos a fazenda figura como o lugar do "mato", como reconhecem a caatinga, que progressivamente vai sendo substituída por roças e casas, sendo a paisagem do lugar progressivamente transformada, num movimento que os velhos narram como "a mudança do mato pra cerca”. Nesse movimento, onde inicialmente, no "tempo dos antigos", só se via a caatinga e grandes fazendas de gado, passa-se a perceber o florescimento das roças e o desmembramento das fazendas de gado em pequenas propriedades, agora delimitadas por cercas de arame farpado. Essa passagem da fazenda de gado para a pequena propriedade pode ser tomada como um importante marco na memória do lugar, que parece nortear as narrativas de grande parte dos velhos entrevistados, influenciando sobremaneira seu olhar sobre a paisagem, iniciando um percurso que culminaria, segundo o olhar dessas pessoas, na constituição das comunidades na regiáo.

No espaço-tempo da fazenda narrado pelos mais velhos, a figura do fazendeiro, o grande proprietário, aparece como sinônimo de riqueza e prestígio - essencialmente ligados à condição de proprietário da fazenda, identificando não apenas o direito de dispor de um bem ma- 
terial, mas também o valor simbólico ou imaterial que se traduz na condição social ocupada por um "proprietário" e, sobretudo, "proprietário" do bem mais precioso aos agricultores: a terra. Além disso, não apenas o valor monetário da terra está em jogo nessa relação entre fazendeiro e fazenda, mas também, e principalmente, a reputação que este constrói localmente, fruto das relaçóes de reciprocidade que estabelece com os agricultores que trabalham em sua fazenda, seja pela "trocas de favores" ou pela formação de novos vínculos de parentesco, principalmente por compadrio.

Entretanto, estas relaçóes de reciprocidade não permanecem nas geraçóes seguintes de herdeiros, que em geral não participam mais da sociabilidade do lugar, por terem perdido os vínculos identitários com a fazenda, morando em outras localidades. Somado a este rompimento do vínculo identitário - que se concretiza derradeiramente com a morte do fazendeiro -, os herdeiros da fazenda ainda se defrontam com o problema do aumento dos tributos sobre a terra, que os encorajavam a vendê-la.

O papel da família é também fundamental para compreender este componente imaterial da propriedade, à medida que é na relação hierárquica fundada na família que o acesso à propriedade da terra se realiza (Woortmann, 1990). Esta representação torna-se clara em algumas narrativas de velhos moradores, que chegam a atribuir a venda de algumas fazendas não apenas a questóes materiais, como o aumento dos tributos, mas também ao fato de que o herdeiro era solteiro, o que, em sua ótica, contitui um empecilho à realização plena da propriedade.

Por outro lado, está presente nas narrativas de grande parte dos velhos a mudança nas relaçóes de apropriação da terra, que parecem ter influenciado em grande parte a relaçáo dos agricultores no ambiente, proporcionando grandes mudanças na paisagem do lugar. Neste sentido, é comum a menção ao desmembramento das fazendas de gado em "posses", aqui compreendidas como pequenos lotes de terra que são postos à venda pelos herdeiros de uma grande propriedade. Essas "posses”, assim que compradas, inauguram uma nova relação do agricultor com a terra e também novas relaçôes de trabalho, na medida em que, em geral, são os próprios trabalhadores das fazendas - os vaqueiros, ou ainda antigos moradores, que compram tais "posses" e se tornam "donos" e, como "donos", dão início ao cercamento de suas propriedades e ao plantio de suas culturas.

Entretanto, a terra, longe de ver-se aí reduzida a mera mercadoria, constitui-se para os agricultores num elemento essencial de sua reprodução social, à medida que a ela tecem-se redes de reciprocidade e trocas simbólicas que fortalecem o patrimônio do agricultor, enfim, sua herança imaterial (Levi, 2000), que ultrapassa os limites impostos pelo título de propriedade.

Isto significa dizer que a propriedade de um agricultor pode ser reconhecida como patrimônio da coletividade das pessoas do lugar que, pelos vínculos de parentesco e vizinhança, teriam, de algum modo, acesso aos recursos e saberes contidos e referentes a esta propriedade. Enfim, as redes de sociabilidade que se desenvolveram em torno da família nas fazendas teriam possibilitado que a terra (bem como os recursos aí disponíveis) tenha sido de algum modo percebida como um bem coletivo. Esse caráter conferido à terra é ainda mais forte quando a esse imaginário associa-se um "mito da ancestralidade", no qual haveria a figura de um "herói desbravador" ou "pai fundador", reconhecido pelas pessoas do lugar por seus feitos na "abertura" de uma fazenda após seu desmembramento, ou seja, sendo o responsável pelo surgimento das primeiras roças. Todas as pessoas do lugar tendem, então, a estabelecer um vínculo de parentesco com tal figura, configurando-se como seus descendentes. 
O trabalho na roça é também um elemento central da sociabilidade da fazenda para os velhos entrevistados, sendo mencionado como responsabilidade de toda a família. Esse compromisso da família se associa, muitas vezes, à lógica da reciprocidade manifesta na preparação da terra para o cultivo mediante a derrubada da caatinga, ou seja, ao "abrir um roçado", bem como na construção de "tanques" (reservatórios destinados à captação de água nos períodos chuvosos). Em geral, são os "batalhões" ou o "boi roubado" que materializam essa lógica.

Os "batalhōes", característicos do espaçotempo da fazenda, envolviam um grande número de pessoas, entre vizinhos e parentes dispostos a trabalhar ajudando a "fazer o roçado" ou "abrir o tanque" de uma família que, em troca, oferecia uma criação (aves, carneiro, bode ou boi, dependendo das condições econômicas da família) para refeição de todos. Esses batalhóes, mais que momentos de trabalho, caracterizavam-se como festas, que iniciavam num dia e só terminavam no outro, quando se "cantava, dançava, batucava".

Nos "batalhóes", os homens e mulheres tinham seus papéis bem definidos. A questão de gênero aparece claramente, tal como percebido nas etnografias de Heredia (1979) e Garcia Jr. (1983), como um dos elementos constitutivos do modo de vida camponês. Assim, enquanto aos homens estava destinado o "trabalho na roça”, considerado como um "trabalho duro", às mulheres cabia a tarefa de preparar os alimentos e cuidar para que todos estivessem bem alimentados para dar continuidade à preparação do roçado.

Assim, o trabalho, trabalhar na roça, trabalhar a terra, parece constituir uma referência importante na dinâmica do cotidiano do lugar e na constituição de sua ruralidade, elemento que claramente transcende o espaço-tempo da fazenda e perpetua-se no chamado "tempo da comunidade". Aprende-se a trabalhar desde criança e trabalha-se a vida toda. Apesar da idade avançada, os velhos permanecem envolvidos com o trabalho na roça, mesmo que num ritmo mais lento. Trabalhar na terra aparece como sinônimo de "coisa boa", de continuar vivo.

Sendo um aspecto importante do espaçotempo da fazenda, o trabalho insinua-se como uma dimensão em que família, gênero e relaçôes de reciprocidade parecem se cruzar na reproduçáo social do lugar, estando fortemente presente nas memórias e narrativas dos mais velhos. Por outro lado, o "trabalho da roça" se constitui comumente como um saber para estes agricultores, o único saber que dizem possuir, saber este que confere uma importante distinção entre o "povo" do campo e os "sabidos" da cidade. É sob esta distinção entre os "sabidos" da cidade e o "povo" da roça que se constitui um discurso a partir do qual se inicia a vida em comunidade em Valente.

\section{Inaugurando o espaço-tempo da comunidade em Valente}

No seio das fazendas instaura-se, a partir do início da década de 1970, a comunidade, como um novo espaço-tempo, a partir do qual se inserem novas sociabilidades no cotidiano vivido pelos agricultores do sisal em decorrência do que as pessoas do lugar reconhecem como uma ressignificação dos trabalhos da igreja católica na região. Em busca de uma compreensão dos sentidos atribuídos à comunidade no lugar, procedo aqui a uma interpretação dos diversos processos desencadeados no seio da igreja que culminaram na constituição de distintas comunidades em Valente.

Contudo, a compreensão dos sentidos de comunidade em Valente requer uma delimitação conceitual prévia, enfim, uma descrição dos modos como os moradores do lugar definem sua comunidade e no que esta definição se 
aproxima ou mesmo se afasta de sua definição do que seria a fazenda. Para tanto, recorro aqui a descriçóes presentes tanto nas narrativas dos moradores mais velhos, quanto naquelas de moradores mais jovens, à medida que estas se apresentam um tanto destoantes, o que contribui para a complexidade e diversidade de sentidos atrelados ao termo.

Inicialmente, pode-se perceber um primeiro sentido de comunidade, fortemente atrelado à noção de localidade, ou ainda a um lugar de referência, principalmente de moradia e de mapeamento de relaçóes sociais (Macedo, 1986; Comerford, 2003). Esta localidade, lugar de referência, constitui-se fundamentalmente a partir das relaçóes de parentesco, de compadrio, amizade ou vizinhança, na qual a afetividade é constantemente acionada como constitutiva do lugar (Tuan, 1980), compreendida aqui como uma herança da sociabilidade do "tempo de fazenda", o que de algum modo caracteriza certa continuidade de relaçóes entre estes dois espaços-tempos distintos. Assim, perceber-se membro de uma comunidade seria, antes de tudo, residir ou, em alguns casos, descender de uma família que reside na comunidade, assim "fazendo parte" dela, mesmo que nela não mais resida.

Por outro lado, transparece ainda na noção de comunidade formulada pelas pessoas do lugar uma clara oposição entre o que seria a "zona rural" (o campo, onde se situam as comunidades), e a cidade ("O Valente", no qual se situam os bairros). Neste sentido, a comunidade contribui para a produção de novas relaçóes campo-cidade, a partir das quais se busca conferir à comunidade destaque e proeminência com relação à cidade.

É neste sentido que as pessoas do lugar se referem à memorável (entre os mais velhos e os mais novos) oposição suscitada entre o "trabalho da enxada" e o "trabalho da caneta", advinda dos chamados "trabalhos comunitários" ao longo da década de 1970. Esta oposição de algum modo contribuiu para reforçar uma representação que não apenas valoriza o trabalho agrícola, mas recria um rural como um sistema de valor (Mormont, 1989) que se contrapóe e ao mesmo tempo busca subordinar o urbano, numa tentativa de construir um elo identitário que viesse a servir de base para a participação e ação "comunitárias", o que para as pessoas do lugar estaria para além das relações estritamente familiares, mesmo que se parta destas relaçóes como fermento para a ação em comunidade. Ao que parece, aí estaria presente o que compreendo como um divisor de águas entre a sociabilidade de fazenda e a sociabilidade que inaugura o espaço-tempo da comunidade.

Por outro lado, a noção de comunidade surge como um conceito tipicamente externo ao lugar, à medida que as pessoas que aí residem atribuem esta noção à presença de religiosos católicos, sem os quais não teriam surgido as comunidades. Alguns entre as geraçóes mais jovens, que participaram desse movimento de constituição de comunidades, chegam a mencionar que estes religiosos teriam "batizado" as comunidades, já que teriam sido eles a reconhecer no seio das fazendas elementos de uma "vida comunitária”, inaugurando a partir dessas fazendas as comunidades. Assim, podemos pensar o papel que a igreja católica tem desempenhado no lugar como promotora de um conjunto representaçôes e práticas advindas de uma ordem distante (Lefebvre, 1991), que se imiscuem ao magma de significaçóes imaginárias do lugar (Castoriadis, 1982), passando a ser reconhecidas por muitos até mesmo como uma "inerência" do lugar, no sentido de terem sido "naturalizadas" como categorias dadas, enfim, como uma das "vocaçôes" do lugar, num processo semelhante ao que ocorreu com o sisal.

Assim imiscuída ao lugar, a noção de comunidade, inicialmente estrangeira, passa a constituir um importante elo identitário no lugar, passando a ser fundamental no processo 
de enraizamento (Weil, 2001) e/ou pertencimento ao lugar, que parece ter sido o foco dos trabalhos da igreja na região, ao menos ao longo da década de 1970. Vale ressaltar que este pertencimento não significa "isolamento" ou "fixação" ao lugar, mas, acima de tudo, que o lugar passa a ser tomado como uma referência, que de algum modo informa as vivências cotidianas das pessoas, mesmo que estas se desloquem a outros lugares.

Desse modo, a comunidade, incorporada como noção inerente ao lugar, parece ter influenciado significativamente as estratégais de enraizamento em Valente. Daí a importância de se compreender como o processo de mobilização se deu no seio da igreja e se imiscuiu nessas "raízes", emaranhando-se para constituir novos elos de pertencimento dos grupos sociais que aí convivem, a partir do qual se constrói no lugar uma "história das comunidades".

\section{Sobre a "história das comunidades": narrativas sobre $o$ processo de mobilizaçáo social em Valente}

Dada a complexidade do processo de constituição desse novo espaço-tempo em que se constitui a comunidade, empreenderei aqui uma análise de três momentos distintos desse processo, ao longo dos quais novos sentidos são atribuídos às comunidades, tomando por base o depoimento de lideranças de três comunidades que considerei típicas de momentos distintos desse processo em Valente.

Entretanto, neste caminho rumo à compreensão dos sentidos da comunidade, considero fundamental uma discussão, mesmo que preliminar, em torno dos processos de mobilização social que tiveram lugar em Valente, em particular aqueles que se deram por intermédio do Movimento de Evangelização Rural (MER) até a década de 1970, bem como aqueles as- sumidos pelo sindicato de trabalhadores rurais (STR) e associações comunitárias após a redemocratização, reconhecidos como berços das distintas comunidades que floresceram no município. Para tanto, tomarei como base a narrativa de um dos militantes do MER que atuaram na década de 1970, bem como de lideranças comunitárias do lugar (não coincidentemente, também lideranças sindicais em Valente). A partir dessa breve apresentação dos princípios de ação comunitária, desenvolvo então uma narrativa sobre os distintos processos de constituição de comunidades em Valente.

\section{O MER, o sindicato e associaçóes e seus prin- cípios de açáo comunitária em Valente}

O Movimento de Evangelização Rural (MER), como uma grande diversidade de movimentos de esquerda durante a década de 1970, encontrou na igreja católica uma espécie de "abrigo" para desenvolver-se, o que teria possibilitado uma importante mobilização social que, em Valente, se traduziu na organização política de uma massa de camponeses que culminou na formação das primeiras comunidades e numa reorientação política do Sindicato de Trabalhadores Rurais (STR). A parca literatura gerada em torno da experiência do MER tem indicado a forte preocupação do movimento com a formação de suas lideranças por meio da valorização do trabalho do campo e do fortalecimento de instrumentos legais de luta (Geacomelli, 2003). Dentre estes instrumentos, o mais proeminente é, sem dúvi$\mathrm{da}$, o sindicato de trabalhadores rurais; daí a referência ao MER na literatura estar, de algum modo, vinculada ao sindicalismo rural (Carvalho Rosa, 2004; Geacomelli, 2003).

Segundo os depoimentos de militantes que atuaram na década de 1970 em Valente, o MER teria surgido inicialmente em Cajazeiras, na Paraíba, estado onde se registra, mesmo que 
superficialmente, alguma experiência do movimento (Geacomelli, 2003), e que militantes de Valente reconhecem como "o lugar mais original do movimento". O movimento teria sido resultante de uma reavaliação da experiência da Juventude Agrária Católica (JAC), fortemente reprimida no período da ditadura. Com base nesta experiência de Cajazeiras, religiosos italianos teriam decidido por iniciá-lo em Valente, vinculando-o inicialmente à Pastoral Rural, onde encontrou certo refúgio para se desenvolver ao longo da década de 1970.

O foco de ação do MER era fundamentalmente o meio rural, em que pese sua futura ramificação para o meio urbano, principalmente devido ao deslocamento das primeiras lideranças comunitárias para os bairros periféricos da cidade. Este movimento reunia, para os militantes do MER, princípios como reflexão-ação (que inclui leitura bíblica, reflexão do evangelho e ação social), solidariedade, participação e sindicalismo, para destacar os mais fundamentais.

Os principais instrumentos de luta definidos pelo movimento ao longo de seu desenvolvimento em Valente foram as reunióes de lideranças, o apostolado da oração e o sindicato, que parecem sintetizar o elo religioso-sindical presente no MER. As reunióes, no âmbito das comunidades, foram inicialmente concebidas como "círculos bíblicos", nas quais era feita a leitura da bíblia à luz da experiência cotidiana das pessoas que participavam. É importante registrar o papel conferido a essas reunióes como espaços de formação de lideranças e de fortalecimento do movimento, à medida que todas as decisóes e encaminhamentos traçados nas reunióes deveriam obrigatoriamente ser retornados às bases.

O apostolado da oração, como parte da comunidade, foi uma espécie de apropriação de um encontro religioso que tinha lugar na cidade e dos quais participavam, em sua maioria, pessoas advindas da classe média urbana. A leitura de algumas lideranças do movimento era da necessidade de criação desse espaço também na comunidade, na "roça", seja para atrair um maior número de pessoas para o movimento, ou ainda para justificar a presença importante dos agentes eclesiásticos na comunidade, disputando assim espaço com a classe média urbana no campo religioso (Bourdieu, 2005).

O sindicato, por sua vez, é uma das tônicas do MER, que tinha como uma de suas bases a busca da constituição de instrumentos legais para a luta social. Desse modo, as suas lideranças empenharam-se na construção e reconhecimento junto às suas bases dos diversos mecanismos jurídicos de ação, dentre eles os estatutos do sindicato de trabalhadores rurais e associações comunitárias e de bairro.

A partir do início da década de 1980, a igreja (representada principalmente pela figura dos novos clérigos e religiosos que assumem em Valente e região) reorienta seu posicionamento político e, neste contexto de abertura política, redefine seu espaço de poder e representação, firmando o religioso como mola mestra de sua atuação.

A reorientação do papel da igreja católica a partir de inícios de 1980 acarretou na inserçáo de novos agentes no processo de organização de comunidades, possibilitando uma ampliação dos sentidos de comunidade na região, principalmente pelo recurso massivo aos novos instrumentos jurídicos de que dispunham, a partir da abertura política: o estatuto do sindicato e da associaçáo, dentre outros instrumentos legais. Estes instrumentos adquirem então um importante valor nesse momento, chegando a ser considerados em algumas comunidades como ponto de partida para sua organização. Neste sentido, conforme relatam algumas lideranças de comunidades surgidas após 1980, não haveria comunidade sem a criação de um estatuto, sem uma organização em "associação comunitária".

Essa passa a ser uma tônica no discurso dos agentes de desenvolvimento na região, em es- 
pecial o sindicato, que passam a tomar a organização em associaçóes como pressuposto para as chamadas "políticas de desenvolvimento" na região. Tais "políticas de desenvolvimento" incluem a destinação de recursos a fundo perdido, bem como doaçôes diversas, que foram repassadas às comunidades via associações comunitárias. Sob esse viés podemos compreender a construção de prédios escolares, casas de farinha comunitárias e cisternas, que passam a constituir os principais pilares da comunidade, sendo vistos por estes agricultores como sustentáculos dos seus principais meios de reprodução social: a produção da mandioca, a escolarização básica e a melhoria do acesso à água.

\section{Da Fazenda Papagaio à Comunidade Papa- gaio: desvelando os sentidos originais de co- munidade em Valente}

A fazenda Papagaio tem sua história vinculada ao intenso processo de minifundialização que ocorreu na região ao longo dos séculos XIX e XX. Há registros documentais da fazenda desde meados do século XVIII, tendo sido esta cortada pela Estrada das Boiadas, o mais importante caminho percorrido pelas tropas de burro que vinham do Piauí em direção à capital da província da Bahia (Bahia, 1974; Barreto, 2007).

A fazenda Papagaio foi reconhecidamente uma das maiores e mais antigas fazendas da região, conforme narra Seu Ezequias (83 anos), legítimo contador das histórias do Papagaio, principalmente por ser o herdeiro das terras da antiga sede da fazenda, em sua propriedade desde 1949, atualmente com cerca de 260 tarefas (em torno de 110 hectares).

A fazenda, "no tempo do cativeiro", como relata Seu Ezequias, chegou a possuir uma área de "uma légua em quadro", ou 10 mil tarefas (cerca de 4.350 hectares), cujo proprietário seria um fazendeiro absenteísta advindo de Santa Bárbara (município próximo a Feira de Santana). Seu
Ezequias narra toda uma cadeia sucessória da fazenda até chegar a seu pai, "Salu do Papagaio", que teria sido vaqueiro na fazenda. Seu "Salu do Papagaio" ficou assim reconhecido por ter sido o primeiro a "descobrir" o Papagaio, ou seja, teria comprado de um herdeiro cerca de 5 mil tarefas da fazenda e desmembrado em "posses", que foram postas à venda. São essas 5 mil tarefas (a chamada "meia légua de baixo"), compradas por Seu "Salu", que passam a ser referência atual da antiga fazenda.

Em que pese a riqueza de detalhes com a qual Seu Ezequias narra sobre a "história do Papagaio", raramente ele se refere à fazenda como uma comunidade, mesmo porque sua narrativa segue um caminho em torno do "início dos tempos”, numa clara preocupação com o "mito de origem" do Papagaio, em que histórias contadas e recontadas e algumas experiências da infância e juventude são o foco de suas lembranças do passado. É o espaço-tempo da fazenda que norteia as narrativas sobre o seu lugar, donde a comunidade é constantemente invisibilizada. E isto me parece uma premissa de boa parte das narrativas dos velhos agricultores da região: são as relações de reciprocidade familiar e vicinal, bem como de subordinação fazendeiro/vaqueiro, vivenciadas no espaçotempo da fazenda, que fornecem os ingredientes para suas representaçóes sobre o passado e servem de chave de intepretaçáo do presente.

Contudo, é também no Papagaio que se encontram vestígios das primeiras vivências em comunidade relatadas por Dona Angelina (75 anos) e Seu Amado (79 anos), casal que reconhece no trabalho religioso a inspiraçáo para uma reconfiguração nas relaçóes de sociabilidade, inaugurando um novo espaço-tempo, distinto da fazenda. Suas representaçôes do passado estão estreitamente relacionadas às experiências vividas por sua filha, Avani de Lima Cunha, reconhecida como importante liderança comunitária de Valente, na década de 1970. 
Em sua narrativa, a velha agricultora chama a atenção para o principal instrumento e princípio formativo da comunidade: a reunião, privilegiando o trabalho de mobilização no campo, na "roça", onde se inicia o movimento. É notável ainda o valor atribuído à figura dos religiosos, os "padres italianos", que teriam feito o "povo crescer", o "povo ver". Esta menção ao "crescer" e ao "ver" confere a esses religiosos, militantes do MER, um papel fundamental como mentores intelectuais do movimento em Valente e como principais alavancas na formação das primeiras lideranças do Papagaio e no desenvolvimento do MER em Valente e região.

Dada a proximidade familiar de Dona Angelina com Avani, principal liderança do $\mathrm{Pa}-$ pagaio até 1978, grande parte das reunióes passam a acontecer em sua residência, nas quais o MER dava seus primeiros passos de organização em Valente. Devido a isso, e principalmente pelo desfecho da morte da filha, em plena atividade como liderança comunitária, Dona Angelina narra com detalhes o processo de organização da comunidade Papagaio e passa a ser reconhecida como legítima narradora desse processo, um caso raro entre os velhos agricultores entrevistados. A seleção, em sua memória, de lembranças referentes à formação da comunidade, está sempre atrelada ao percurso militante seguido por sua filha, que na narrativa se mistura à trajetória de vida de Avani, numa clara tentativa de explicação dos rumos por ela tomados e, principalmente, de explicação de sua morte. Neste sentido, a lembrança da comunidade adquire para Dona Angelina um significado de "dever-lembrar" a filha, um ícone da mobilização não só no Papagaio, mas em boa parte da região sisaleira.

E esta tônica do "dever-lembrar" ganha proporçóes importantes na região e informa as narrativas de grande parte das lideranças ainda hoje atuantes (ligadas não apenas por laços de amizade, mas principalmente de parentes- co com Avani), bem como dos militantes do MER que atuaram no movimento em Valente, criando um forte sentido de memória atrelado à comunidade, não só no Papagaio, mas em todas as comunidades que se originaram ao longo da década de 1970 por ocasião da militância desse ícone do trabalho comunitário em Valente. Podemos supor que o sentimento de "recusa da morte" (referido ora à pessoa de Avani, ora ao receio de desmobilização, em decorrência da abertura política na qual a comunidade tende a se ressignificar) passa a ser o mote para um movimento de "resgate da memória da comunidade", no qual Avani é tomada como símbolo.

Nesse processo, há um forte apelo à participação das novas geraçóes, principalmente os jovens, aos quais é atribuído o papel de continuidade do movimento, que não pode "morrer", em memória de Avani. Esse apelo à memória, seja pela construção de símbolos do movimento, seja pela referência forte aos "fundadores" da comunidade, parece ter sido um forte componente identitário dos diversos grupos envolvidos na mobilização social que se iniciou na década de 1970 no seio da igreja católica (Assis, 2006). Esse "resgate"1 da memória, principalmente a partir da figura de Avani, tem sido o foco de muitos esforços de formação das futuras lideranças da comunidade. Desse modo, é legado aos jovens, futuras lideranças, o papel de "guarda-memória" 2 . Neste sentido, é legado aos jovens o papel da "sobrevivência do trabalho da comunidade".

Tomados por esse ímpeto em produzir uma memória da comunidade é que as lideranças e militantes do MER entrevistados mostraram-se muito receptivos ao diálogo sobre os sentidos de comunidade em Valente, principalmente como uma forma de registro das narrativas sobre o movimento, ainda pouco sistematizado na região. É neste sentido que Dona Elisa ${ }^{3}$ relata sua experiência no movimento no Papagaio, reforçando o papel dos religiosos nesse processo, 
que começou com a reuniáo. No depoimento desta liderança está constantemente presente a figura messiânica dos "padres italianos", mentores intelectuais do MER, aos quais é atribuído o poder de "fazer ver ao cego". Trata-se de uma compreensão messiânica do movimento que parece ter sido constituída e reforçada por meio das leituras bíblicas, que em grande medida privilegiavam a aproximação fé-vida, como relata Dona Elisa, mas principalmente uma aproximaçáo entre o sagrado e o profano, num importante processo de racionalização do mundo, tendência essa que, de certa forma, aproxima o MER dos ideais do catolicismo da libertação, num processo de "humanização do mundo" (Amaral, 2006).

Em termos de açóes concretas empreendidas na comunidade, os "mutiróes" se caracterizam como marca deste espaço-tempo que floresce na década de 1970. Como outras formas de sociabilidade que encontram seu berço nas fazendas, os primeiros "mutirôes" realizados no Papagaio resgatam as relaçóes de reciprocidade tradicionais dos grupos de parentesco e vizinhança do lugar, amplamente conhecidos como "batalhões", consistindo em trocas recíprocas de serviços e/ou dias de trabalho na roça. Entretanto, é importante a distinção feita pelas lideranças comunitárias entre os "mutirôes" e os "batalhóes", já que esta parece conferir uma delimitação desse novo espaço-tempo para as pessoas do lugar. De acordo com as lideranças, o ponto central de divergência entre estas duas formas de reciprocidade reside numa distinção entre a "festa" - característica dos "batalhôes" - e o "compromisso" - característico dos "mutiróes" em comunidade.

Da reciprocidade festeira, da "folia", teria sido inaugurado na comunidade o compromisso com uma coletividade, no qual o trabalho em "mutirão" na casa de um membro da comunidade obriga a retribuição na forma também de trabalho, não mais de festa ou banquetes servidos aos trabalhadores, característicos dos "batalhóes". Cria-se assim uma sociabilidade na qual o "batalhão" passa a ser concebido como pertencente a outro espaço-tempo, o da fazenda, na qual não haveria o compromisso com uma coletividade para além dos laços de parentesco e/ou vizinhança. Assim, a "festa" do batalhão não seria capaz de estabelecer vínculos de compromisso entre todos os participantes, ao contrário da prática do mutirão, tal como percebem boa parte das lideranças, náo apenas no Papagaio, mas em todas as comunidades que floresceram nesta época.

No avanço dos "trabalhos de comunidade", as lideranças se deparam com um novo contexto político, a redemocratização, que abre novas possibilidades de luta social, mas, por outro lado, cria uma nítida separação entre o espaço religioso e os espaços sindicais. A partir desse momento, criam-se novos sentidos de comunidade, que progressivamente vão se afastando da compreensão inicial de união fé-vida, do recorte religioso-sindical.

Dona Elisa relata uma clara distinção, a partir da década de 1980, entre suas atribuiçôes religiosas (no trabalho da catequese, no envolvimento em pastorais e nas celebraçóes) e suas atribuições na luta sindical e associativista. Essa separação entre "trabalho religioso" e "trabalho social" (como comumente se traduzem a luta sindical e a experiência associativista) implica mudanças importantes nos sentidos de comunidade em Valente, à medida que a comunidade torna-se progressivamente sinônimo de "associação comunitária", ao menos para a grande massa de moradores do $\mathrm{Pa}$ pagaio. Para essa maioria, a comunidade existe independentemente de sua participação social, naturalizando-se na forma de associação, à qual recorreriam para obter benefícios sociais, principalmente a aposentadoria.

É fundamental destacar que ainda está presente no Papagaio uma nucleação familiar 
característica da sociabilidade da fazenda, na qual existem elos importantes de parentesco em torno das famílias Lima e Cunha, de Avani (o símbolo da comunidade), e a família Lopes, do reconhecido "fundador" do Papagaio, Seu Salu do Papagaio. Estas famílias reproduzem em grande medida os elos de afetividade e vizinhança ainda presentes no lugar, o que de algum modo nos remete às noçóes de "nucleação" e "vida comum", tão caras a Redfield (1965). Por outro lado, o contínuo processo de desmembramento de terras ainda presente no Papagaio tem conferido novas conformações à sociabilidade do lugar, principalmente pela inserção de uma grande diversidade de pessoas advindas de outros lugares, que de algum modo perderam essa referência às famílias nucleares da comunidade.

Há que se notar que essa nucleação familiar estende-se para além das fronteiras do Papagaio, de tal forma que mesmo na cidade ("no Valente") é possível encontrar a referência a membros da comunidade, principalmente filhos e netos de moradores da antiga fazenda, que mantêm seu elo de pertencimento ao lugar, seja por visitas contínuas aos parentes, seja pela participação ativa no trabalho agrícola e, ainda, no trabalho de mobilização social. Esses moradores da cidade são, em última instância, membros do Papagaio e desempenham um papel fundamental no processo de enraizamento da comunidade.

Esse delongado percurso pelos sentidos de comunidade no Papagaio justifica-se por esta localidade retratar um processo tipo-ideal (Weber, 1994) de organização comunitária, que surge logo no início da década de 1970, associada à mobilização empreendida pelo Movimento de Evangelização Rural em Valente. Sendo uma das primeiras comunidades que se organizam no campo, ela resume em grande medida a diversidade de movimentos que vivenciaram os agricultores ao longo de seu processo de mobilização social, desde os primeiros movimentos em torno dos "círculos bíblicos" e da organização da catequese, passando pela reorientação política do sindicato de trabalhadores rurais, até o complexo processo de redemocratização que acarretou profundas consequências para as representações em torno do trabalho comunitário.

Desse modo, para se empreender uma análise dos sentidos de comunidade, termo que surge em Valente originariamente a partir dos trabalhos da igreja durante a década de 1970, torna-se fundamental acionar este sentido original da reflexão-ação comunitária no Papagaio. Somente a partir daí é possível apreender a complexidade dos sentidos de comunidade em Valente, principalmente a partir do fim da década de 1970, quando um novo ator se configura no processo - o sindicato de trabalhadores rurais, que assume um lugar relegado pela igreja na mobilização social na região sisaleira.

\section{Da Fazenda Vitória Régia à Comunidade Lua Nova: entre o "trabalbo religioso" e o "trabalbo social"}

O percurso da fazenda Vitória Régia à comunidade Lua Nova segue-se semelhante ao que foi descrito detalhadamente para a fazenda Papagaio, daí a opção por uma descrição mais sucinta desse caminho, tomando com mais detalhes apenas alguns processos que se destacam por sua distinção histórica, o que me faz atribuir a Lua Nova um caráter de "comunidade-tipo" diferente do Papagaio, principalmente pelo papel crucial que o sindicato exerceu em sua formação.

A fazenda Vitória Régia, lugar nuclear da família Pacheco, originou-se provavelmente do desmembramento da antiga fazenda Papagaio, compondo parte da chamada "meia légua de baixo" da referida fazenda, como nos relatou Seu Ezequias, do Papagaio. Aos poucos, a fazenda foi desmembrada por herança aos filhos e netos, que renomearam suas propriedades e, 
ao mesmo tempo, incorporaram novas terras circunvizinhas a estas. Este foi o caso de Seu Marcelo Pacheco, que adquiriu uma porção vizinha de terras, que foi anexada a suas terras e escriturada como Lua Nova. Seu Marcelo, filho mais velho de Seu João Pacheco, herda de seu pai náo apenas uma parcela de terras da fazenda Vitória Régia, mas também a condição de patriarca da família Pacheco, com a morte do pai. Isso certamente o tornou, ao longo do tempo, um legítimo "contador" da história da fazenda, sendo sempre referido nas narrativas dos outros velhos entrevistados.

A legitimidade de Seu Marcelo Pacheco era tamanha que se reconhece nele o elo dessa comunidade, quando de sua organização em fins da década de 1970. Não apenas lideranças comunitárias, mas também militantes do MER apontam a figura de Seu Marcelo como central nesse processo, localizando sua casa como uma espécie de "embriâo da comunidade", por seus esforços no sentido de buscar uma presença mais forte e atuante da igreja católica em sua localidade.

Segundo depoimento de sua principal liderança, a comunidade Lua Nova teria surgido de uma reunião ocorrida na fazenda, com a participação de vários moradores da antiga fazenda Vitória Régia (dentre eles, destaca-se Seu Marcelo) e também de militantes do MER, ainda ativos à época. Nessa reunião "batizouse a comunidade", que perde progressivamente a referência da fazenda Vitória Régia e passa a ser reconhecida como Lua Nova, em referência às terras pertencencentes ao novo patriarca da fazenda, Seu Marcelo.

De modo distinto ao que foi descrito para o Papagaio, Lua Nova tem seu florescimento como comunidade mais estreitamente relacionado ao movimento sindical. Neste sentido, é a partir do contato com lideranças sindicais que futuras lideranças da comunidade Lua Nova entram em contato com os princípios do
MER, principalmente por intermédio de lideranças advindas do Papagaio.

Pode-se supor então a comunidade Lua Nova como uma segunda etapa na constituição de comunidades em Valente, que surge como fruto da reorientação do sindicato, advinda da articulação religiosa-sindical do começo da década de 1970. Essa experiência sindical fez as lideranças atribuírem novos sentidos à comunidade, como fruto do trabalho do sindicato, ou "trabalho social".

O sindicato, como mola mestra nesta sociabilidade comunitária na Lua Nova, passa a ser então o principal instrumento de mobilização social em Valente após a década de 1970, influenciado pelos "trabalhos de igreja". Segundo relatam as lideranças de Lua Nova, ocorreu aí um progressivo afastamento dos militantes pastorais (os reconhecidos "padres italianos") das reunióes, que passaram a ser coordenadas pelas lideranças sindicais, sendo reconhecidas como "reunião de sindicato". Parece-me fundamental esse processo de afastamento do militante pastoral, marcando uma nova etapa de constituição de comunidades, na qual o sindicato assume o papel central de mobilizador social, principalmente a partir de meados da década de 1980, quando ocorre um total afastamento eclesial e se intensifica o apelo à formação de associações comunitárias na região, que passam a ser um marco na formação das comunidades que se originaram nesse período.

\section{Da Fazenda Varginha de Dentro à Comuni- dade Varginha de Dentro: a associaçáo como divisor de águas}

A fazenda Varginha de Dentro originou-se também da compra de uma "posse" de terra por João Salustiano Costa, sendo esta transferida aos filhos por herança. É importante destacar que o que hoje se reconhece como a área da comunidade Varginha de Dentro pertence 
exclusivamente a uma família, os Costa, sendo esta a origem da nucleação característica da localidade. Os mais velhos de seus moradores, filhos de Seu João Salustiano Costa, são unânimes em descrever a casa de seu pai como a sede da "antiga fazenda", hoje transformada em comunidade. Por outro lado, esses velhos são enfáticos ao declarar que pouco sabem da história da comunidade, por conta de não terem participado ativamente desse processo, que atribuem quase exclusivamente a seus filhos, a geração posterior.

Entretanto, Seu Joaquim Costa, velho morador de Varginha de Dentro, reconhece uma marcação espaço-temporal clara entre o "tempo da fazenda" e o "tempo da comunidade", utilizando como marcos diferenciais a construção do "prédio escolar" e, posteriormente, a casa de farinha, a partir dos quais teria "começado a comunidade". Aí reside um elemento diferenciador no processo histórico de formação de comunidades em Valente: a sua constituição atrelada à construção de um "prédio escolar", sem nenhuma referência ao trabalho da igreja católica na região, por meio da figura dos "padres italianos", como está marcadamente presente no depoimento de Dona Angelina, moradora do Papagaio, e mesmo nos relatos de lideranças comunitárias em Papagaio e Lua Nova.

Esta referência ao "prédio escolar" confere novos sentidos à comunidade, que surge já na esteira de um processo de redemocratização, durante o qual há não apenas uma redefinição do papel da igreja, mas também a socialização do papel das associaçóes como instrumentos de luta social no lugar. Recorrendo-se ao depoimento de uma das lideranças de Varginha de Dentro, Seu Paulino Costa, torna-se possível compreender a formação da "comunidade" em estreita relação com a fundação da associação comunitária, em 1989. Esta associação teria se formado em virtude da necessidade de se construírem um prédio escolar e uma casa de farinha, concebidos no lugar como prioridades para o desenvolvimen- to da localidade, que passam a ser reconhecidos como marcos de formação da comunidade.

Seu Paulino reconhece ainda na fazenda uma espécie de "comunidade escondida", que constitui o berço da associação. Mas, no depoimento de Seu Paulino, teria sido esta associação a responsável pelos chamados "trabalhos sociais" na localidade e, consequentemente, do espaço-tempo da comunidade Varginha de Dentro. Nota-se aí uma clara tentativa de transformação das relaçôes de sociabilidade características da fazenda, inserindo a marca dos chamados "trabalhos sociais", enfim, da mobilização social a partir de instrumentos legais, como o sindicato e as associaçóes.

Criar uma comunidade como uma coletividade para além da família e para além dos limites da fazenda seria, em última instância, a finalidade da associação para Seu Paulino. E é neste sentido que se pode considerar a comunidade Varginha de Dentro como fruto da associação, um instrumento jurídico que burocratiza e racionaliza a vida cotidiana, inserindo aí novas formas de sociabilidade, o que permite um maior alcance das reivindicaçóes do grupo.

No momento da fundação da associação, vale notar o papel crucial desempenhado por lideranças comunitárias de outras localidades, principalmente Lua Nova, na assessoria jurídica às lideranças de Varginha de Dentro, por conta de sua experiência comunitária e, principalmente, sindical. Desse modo, pode-se dizer que a comunidade Varginha de Dentro foi fruto de um esforço de incorporação de um viés essencialmente "social" (leia-se "sindical"), onde se privilegia a associaçáo como um importante instrumento de mobilização e luta social.

Por outro lado, com a instituição do instrumento jurídico (a associação), parece ter havido um progressivo afastamento do princípio de reflexão-ação subjacente ao sentido original de "comunidade" desenvolvido no início da década de 1970, vinculado essencialmente à mobi- 
lização desencadeada pelo MER. No momento em que a associação tomou para si a função dos "trabalhos sociais", sedimenta-se um sentido de comunidade essencialmente normativo, à medida que organizar-se em comunidade parece ter passado a ser um pré-requisito para a obtenção de crédito, auxílios previdenciários e obras de infra-estrutura que beneficiem a localidade. Esta parece ter sido a tônica de diversas comunidades que foram criadas a partir do fim da década de 1980, ao menos na ótica de suas lideranças, tal como ficou explícito no relato apresentado por Seu Paulino.

\section{Entre o velbo e o novo: a comunidade fincan- do raízes na fazenda}

O percurso pelas narrativas sobre o processo de formação das comunidades em Valente aqui desenvolvido tornou possível uma aproximação aos sentidos de comunidade presentes entre os agricultores do sisal, principalmente no que tange à sua delimitaçáo como um espaçotempo diferente e posterior ao espaço-tempo da fazenda. Estes sentidos de comunidade não são unívocos nem excludentes, e de certa forma se orientam pelo percurso de formação das comunidades em Valente e representam uma tentativa de forjar uma identidade que possibilite o enraizamento das pessoas em seu lugar.

Destaca-se, de início, a presença de um sentido de comunidade advindo do desencantamento do mundo porporcionado pelo MER na região, que de algum modo se sobrepôs àquele sentido encantado das fazendas, nas quais predomina uma sociabilidade fundamentada por um catolicismo popular e por uma forte nucleação familiar, que permanece como referência nas localidades estudadas. Este sentido de comunidade tende a privilegiar os laços de solidariedade coletiva, constituídos fundamentalmente a partir dos laços de pa- rentesco já sedimentados na fazenda, mas que ultrapassariam, para as pessoas do lugar, os limites dessas redes familiares. Também chamam a atenção nesse dito "sentido original de comunidade" os princípios de união fé-vida e de reflexão-ação, nos quais se torna fundamental o viés religioso-sindical característico do MER. Transparece mais claramente esta representação de comunidade naquelas localidades em que o MER atuou diretamente, ao longo da década de 1970. É nesse momento que o termo "comunidade" se constrói e enraíza no interior das antigas fazendas, transmutando-se da oposição campo-cidade, à medida que é no rural, na roça, que se constitui a comunidade, fruto do "trabalho da enxada" e da reflexão em torno de sua subordinação à cidade, ou ao "trabalho da caneta".

Por outro lado, já a partir do fim da década de 1970, constroem-se novos sentidos de comunidade, vinculados principalmente à progressiva delimitação de funçôes sociais entre igreja e sindicato, que se acirra a partir da redemocratizaçáo. Assim, constituem-se um sentido estritamente religioso, particularmente atrelado ao trabalho de catequese, e outro relacionado ao que foi denominado no lugar por "trabalho social", tendo como representante maior o sindicato. Podemos ainda considerar um outro sentido de comunidade, no qual o apelo à memória está presente como cerne. Aí, privilegiase uma espécie de "resgate" da memória da comunidade e de seus princípios originais, tomando como elemento agregador a construção de símbolos comunitários na região.

Por outro lado, os velhos, como guardiōes da memória de um espaço-tempo anterior, o da fazenda, em geral "não sabem" e não se reconhecem como partícipes da comunidade, que ainda permanece viva na memória como fazenda para eles. E é a partir dessa memória da fazenda (o "tempo do velho") que desenvolvem seu processo de pertencimento ao lugar, 
tomando como principais elementos a sociabilidade familiar, o espaço-tempo da fazenda e sua propriedade, o trabalho da roça, a convivência com a seca, dentre outros elementos que constituem sua vivência cotidiana e que a partir deles constituem suas representações sobre o passado. Por outro lado, as novas geraçóes tecem seu cotidiano sedimentado no espaço-tempo da comunidade (o "tempo do novo"), da coletividade para além das redes familiares, a partir do qual se enraízam ao lugar. Assim se entrelaçam em Valente as vivências de pelo menos três gerações, que cotidianamente trocam experiências e constituem seu vivido tomando como base a sociabilidade da fazenda que, transmutada em comunidade, abre-se como palco de novas formas de sociabilidade e de pertencimento ao lugar.

\section{From "Farm" to "Community": space-ti- mes rooted in the sisal region of Bahia}

abstract This article aims at understanding the plurality of meanings assigned to the "community" in the sisal region from two points of departure: the community is firstly considered as a space-time formed at the beginning of the 1970's, marking the beginning of a process of social mobilization; it is then understood as a locality, for processes of social mobilization happen within the geographical space of the farm, which gradually coincides with the community, and then becomes not only a reference of "social work", but also a place. It is thus possible to suppose a road leading from "farm" to "community", as a process of production of a new space-time. The analysis of the meanings of "community" in the region is based on the narratives of its oldest inhabitants, as well as of community leaders and advocates of the Rural Evangelization Movement (MER) who have been active in the region since the 1970's.

keywords Memory. Community. Space-time. MER. Sisal Region.

\section{Notas}

1 É comum a referência de "resgate" da memória entre as lideranças do movimento, o que nos remete a um recorte tipicamente bergsoniano para a questáo da memória e sua produção no lugar.

2 Faço aqui referência a Philippe Lejeune (1997) e sua experiência na organizaçáo de um arquivo autobiográfico na França. Recorro a essa expressão por assim entender a recente preocupação de algumas comunidades de Valente em produzir um acervo documental sobre a memória do seu lugar, papel na maior parte das vezes atribuído aos jovens dessas comunidades, ou mesmo apropriado por eles.

3 Vale lembrar que os nomes de localidades e pessoas que aparecem em itálico neste artigo se referem a nomes fictícios, visando preservar a identidade dos entrevistados. Os demais nomes são reais, à medida que disponho de autorização expressa para sua identificação.

\section{Referências Bibliográficas}

AMARAL, Roniere R. Milagre politico: catolicismo da libertação. Tese (Doutorado em Sociologia). Universidade de Brasília, Brasília, 2006.

ASSIS, João Marcus F. Novas configuraçôes da memória no catolicismo da Diocese de Nova Iguaçu - RJ. In: Encontro Regional de História. 12, Niterói, Anais... Niterói: UFF, 2006.

BAHIA. Análise global da economia baiana: diagnóstico. Salvador: SEPLAN, 1974.

BARreto, Orlando M.. Conceição do Coité: da colonização à emancipação. Conceição do Coite: Nossa Gráfica, 2007.

BOSI, Ecléa. Memória e sociedade: lembranças de velhos. 2. ed. São Paulo: T. A. Queiroz, 1983. (Série Estudos Brasileiros, 1)

O tempo vivo da memória: ensaios de psicologia social. São Paulo: Ateliê Editorial, 2003.

BOURDIEU, Pierre. O poder simbólico. 8. ed. Rio de Janeiro: Bertrand Brasil, 2005.

BOURDIEU, Pierre. $A$ distinção: crítica social do julgamento. São Paulo: Edusp, 2007.

CARVALHO ROSA, Marcelo. Sobre os sentidos das novas formas de protesto social no Brasil: os impactos das açóes do MST sobre o sindicalismo rural. In: GRIMSON, A. La cultura en las crisis latinoameri- 
canas. Buenos Aires: CLACSO, 2004. Disponível em: <http://bibliotecavirtual.clacso.org.ar/ar/libros/ grupos/grim_crisis/04sobre\%20os\%20sentidos.pdf>. Acesso em: 01. Out. 2009.

CASTORIADIS, C. A instituição imaginária da sociedade. 3 ed. Rio de Janeiro: Paz e Terra, 1982.

COMERFORD, John. C. Como uma família: sociabilidade, territórios de parentesco e sindicalismo rural. Rio de Janeiro: Relume Dumará: Núcleo de Antropologia Política/UFRJ, 2003 (Coleção Antropologia da Política, 22).

ELIAS, Norbert. Sobre o tempo. Rio de Janeiro: Jorge Zahar, 1998.

GARCIA Jr., Afrânio R. Terra de trabalho. Rio de Janeiro: Paz e Terra, 1983. (Coleçáo Estudos sobre o Nordeste, 8)

GEACOMELLI, Gabrielle. Aprendendo por uma história de pastoral popular: o sindicato dos trabalhadores rurais de Mogeiro - PB (meados dos anos sessenta e primeiros dos setenta). 2003. Disponível em: <http: /www.paulofreire.ufpb.br/ paulofreire/Files/seminarios/oral34.pdf/>. Acesso em: 13. mar. 2009.

HEREDIA, B. M. A. A morada da vida. Rio de Janeiro: Paz e Terra, 1979. (Série Estudos sobre o Nordeste, 7)

IBGE. Indicadores Agropecuários 1996-2003. 2005. Disponível em: <http://www.ibge.gov.br/home/estatistica/economia/agropecuaria/indicadoresagro_19962 003/default.shtm//>. Acesso em: 14 nov. 06.

IBGE. Valente - Bahia. Histórico. 2008. Disponível em: <http://biblioteca.ibge.gov.br/ visualizacao/dtbs/ bahia/valente.pdf $>$. Acesso em: 13 nov. 08 .

LEFEBVRE, Henri. The production of space. Oxford: Blackwell Publishing Ltd, 1991.

LEFEBVRE, Henri. La presencia y la ausencia. Contribuición a la teoría de las representaciones. México: FCE, 2005 [1980].

LEJEUNE, Philippe. O guarda-memória. Estudos Históricos, n. 19, 1997.
LEVI, Geovani. Usos da biografia. In: FERREIRA, M. M., AMADO, J. Usos \& abusos da história oral. Rio de Janeiro: Fundação Getúlio Vargas, 1996. p. 167-182. A herança imaterial. Rio de Janeiro: Civilização Brasileira, 2000. Titulo. Local: Editora, 1996.

MACEDO, Carmen C. de A. Tempo de gênesis: o povo das comunidades eclesiais de base. São Paulo: Brasiliense, 1986.

MORMONT, Marc. Vers une redéfinition du rural. Recherches Sociologiques, v. XX, n. 3, p. 331-350, 1989.

OLIVEIRA, Vanilson. Conceição do Coité e os Sertôes dos Tocós. Conceição de Coité: Clip Serviços Gráficos, 2002.

PINTO, Maria N. Contribuição ao estudo da influência da lavoura especulativa do sisal no estado da Bahia. Revista Brasileira de Geografia, v. 31, n. 3, p. 3-102, 1969.

POLLAK, Michel. Memória, esquecimento, silêncio. Estudos Históricos, v. 2, n. 3, p. 3-15, 1989.

REDFIELD, R. The little community and peasant society and culture. Chicago: university of Chicago Press, 1965.

SILVA, Odilon R. R. da; BELTRÃO, Napoleão E. M (Orgs.). O agronegócio do sisal no Brasil. Brasília: EMBRAPA-SPI; Campina Grande: EMBRAPA-CNPA, 1999.

TUAN, Yi-Fu. Topofilia: um estudo da percepção, atitudes e valores do meio ambiente. São Paulo: DIFEL, 1980.

WEBER, Max. Economia e sociedade: fundamentos da sociologia compreensiva. 3 ed. Brasília: UNB, 1994.

WEIL, S. O enraizamento. Bauru: EDUSC, 2001. (Coleção Mulher).

WOORTMANN, Klaas. "Com parente náo se neguceia": o campesinato como ordem moral. Anuário Antropológico, v. 87, p. 11-73, 1990.

\title{
autora Alessandra Alexandre Freixo \\ Professora Assistente do Departamento de Educação/UEFS \\ Doutoranda em Ciências Sociais CPDA/UFRRJ
}

\author{
Recebido em 25/03/2009 \\ Aceito para publicação em 06/11/2009
}

